\title{
Analyzing the Gender Gap in Financial Literacy
}

\author{
Bettina Greimel-Fuhrmann ${ }^{1}$, Maria Silgoner ${ }^{2}$ \\ Vienna University of Economics and Business ${ }^{1}$ \\ Oesterreichische Nationalbank ${ }^{2}$ \\ Austria
}

\begin{abstract}
Studies have repeatedly shown that women answer less financial knowledge questions correctly than men. Hence, they are often identified to be a financially 'vulnerable' group who needs more attention in financial education. This paper explores if this holds true for the Austrian population. A survey among 2,000 respondents reveals that Austrian men outperform women in terms of financial knowledge, even if we control for different socio-demographic characteristics and response behavior. However, women seem to be less prone to spending money, are more risk averse and watch their financial status more closely. In a multiple regression analysis, knowledge, attitudes and behavior are relevant for explaining financial well-being, but gender is not. Thus, it seems that women are not necessarily a financially vulnerable group but might benefit from acquiring more financial knowledge and gain more selfconfidence in making financial decisions.
\end{abstract}

\section{Introduction}

Recent empirical studies - some of them largescale and international - reveal that in most countries, a considerable number of people lack even basic financial knowledge and understanding. These studies also show that men tend to outperform women in standard financial literacy surveys [1, 2]. Several reasons have been put forward for this gender gap, ranging from different answer behavior, to gender differences in financial interest and involvement or in other personal characteristics. Other studies show that there are also gender differences in behavior and attitudes, which are at least partly the result of differences in knowledge. All three factors knowledge, attitudes and behavior - are supposed to be interrelated and to affect financial well-being [2, 3, $4,5]$. Nowadays, the lack of financial literacy matters more than ever, given the increasing complexity of financial products and economic relationships. The observed gender gap, indicating larger knowledge gaps of women, is especially problematic because of long life expectancies of women and a wide variety of biographies.

The objective of this paper is to examine if a gender gap in financial literacy can also be confirmed for Austria, using survey data on financial literacy of the Austrian population. The analysis focuses not only on potential differences in knowledge, but also on financial behavior and money attitudes. We will finally examine whether there is a gender gap in explaining financial well-being which is the overall objective of being financially literate [1].

\section{Related Work}

There is no universally accepted definition of financial literacy. Many studies refer to the rather broad definition of financial literacy used by the Organisation for Economic Co-operation and Development (OECD) and its International Network on Financial Education (INFE). While other definitions focus on financial knowledge, the OECD/INFE definition integrates financial knowledge, skills, attitudes and behavior, as well as their mutual relationships, characterizing financial literacy as 'a combination of financial awareness, knowledge, skills, attitude and behavior necessary to make sound financial decisions and ultimately achieve individual financial well-being' [1]. Though definitions of financial literacy may differ, there is no single definition, concept or competence model of financial literacy that does not include financial knowledge [2].

There is ample literature showing that there is a financial knowledge gender gap in favor of men. Bucher-Koenen et al. [3] show that there is a significant gender gap in the US, in Germany and in the Netherlands. Arrondel et al. [4] present similar results for France. Several reasons have been put forward for this observation:

The gender gap may be partly the result of female respondents differing systematically from male respondents in socio-demographic characteristics such as education, work experience, responsibility for financial matters, marital status or income. Regression 
analyses controlling for these factors typically manage to reduce the gender gap considerably [6]. Nevertheless, the gender gap does not vanish and remains statistically significant.

Alternatively, the gender gap may be the result of different response behavior in test settings. It seems that women tend to admit more often than men that they do not know the correct answer instead of just trying the most probable guess [7]. A carefully designed, gender neutral survey may help to reduce this bias [1].

Some studies focus on the role of the traditional division of tasks within households and the special role of financial responsibilities. If men make the majority of financial decisions, they will develop financial literacy while women will lose financial skills. For the U.S., however, Fonseca et al. [6] do not find strong support for specialization by gender. Brown and Graf [7] show that the gender gap in financial literacy is stronger for singles than for married respondents, contradicting the division of task hypothesis. Bucher-Koenen et al. [3] find a gender gap in knowledge not only for married, but also for single, divorced or widowed respondents, and so does Hsu [8].

The gender gap in knowledge may also be the result of differences in interest in financial matters. Lührmann et al. [9] show that girls' financial interest is about $10 \%$ lower than that of boys. They also find a gender gap in self-assessed financial literacy. According to Brown and Graf [7], 45\% of male respondents report to have followed the financial crisis closely, while only $23 \%$ of females did so. However, they do not find evidence that this lack of financial interest is responsible for the gender gap in financial literacy. Interestingly, there is some evidence that the gender gap is much smaller or insignificant in formerly communist, more egalitarian countries $[3,10]$.

As far as financial attitudes are concerned, Atkinson and Messy [1] find that women are more likely to have a positive attitude towards long term planning. Women are also more risk-averse than men [11] but less confident when making financial decisions [12].

As to financial behavior, Mottola [13] finds that women with low levels of financial knowledge are more likely than men to show costly credit card behavior such as paying fees for settling the credit card bill late. However, among men and women with high levels of financial knowledge there is no such gender gap in behavior. He thus concludes that financial education may help eliminating this gender gap. Atkinson and Messy [1] find that women are less likely to gain high scores for financial behavior than men. Interestingly, gender differences in financial knowledge are, however, not entirely reflected in financial behavior, maybe because many financial decisions are undertaken at a household level while knowledge is measured individually. Stock market participation is much lower among females than among men and this is - according to van Rooij et al. [14] partly explained by the lower level of financial literacy. Lührmann et al. [9] show that teenagers with low financial literacy are less aware of the running costs of mobile phones and more likely to be highly indebted.

\section{Research Design}

The Austrian dataset is based on 2,000 face-to-face interviews, conducted in late autumn 2014. The survey comprised 1,994 computer-assisted personal interviews (CAPIs) from October to November 2014. The non-response rate was about $30 \%$. If not indicated differently, we use survey weights to produce descriptive population statistics throughout the paper. The weights consist of a combination of sampling/design weights and poststratification weights based on external population statistics on age and gender at the province level.

The survey is integrated into the 'Measuring Financial Literacy' initiative of the OECD's International Network on Financial Education (INFE) that intends to run a unified and extended survey on financial literacy in a wide range of countries $[1,15]$. It consists of questions on financial knowledge, financial behavior and attitudes that are part of the OECD's Toolkit for Measuring Financial Literacy [1, 16] and is supplemented by a set of demographic and socioeconomic variables. A pilot study was carried out in 14 countries in 2010 and 2011 [1].

The full Austrian questionnaire is available from the authors upon request. Along with items covering experience with financial products and financial decisions, it covers a total of 11 knowledge questions, 8 questions on financial behavior and 15 questions on money attitudes.

\section{The Gender Gap in Financial Know- ledge Is Confirmed}

The knowledge questions range from simple division tasks or the understanding of concepts such as inflation or the link between risk and returns, to more sophisticated questions on compound interest rates, the consequences of exchange rate developments on foreign currency loans or the link between interest rates and bond prices. None of these questions requires expert knowledge [16].

As to the Austrian dataset, there are important knowledge gaps throughout the population. On average, only $4 \%$ of the respondents managed to answer all 11 questions correctly. There are considerable differences across gender: While $7 \%$ of males give correct answers to all 11 questions, this share is as low as 3\% for women, as shown in Figure 
1. The distribution of the knowledge scores of men is also more skewed to the right than those of the female respondents.

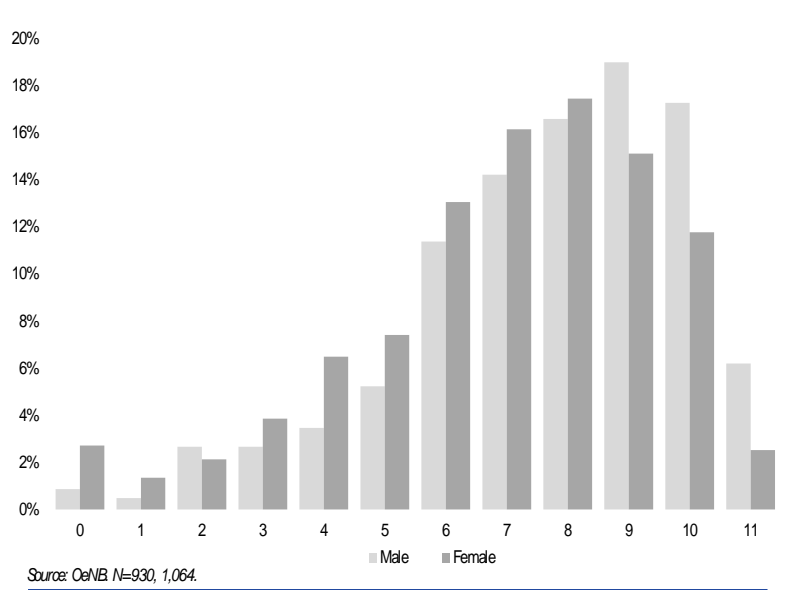

Figure 1. Percentage of Respondents Answering x Financial Knowledge Questions Correctly

Figure 2 shows that most men and women manage to answer simple questions correctly (simple division, understanding that lending EUR 25 today and getting EUR 25 back the next day implies an interest of zero, understanding that higher return usually comes at higher risk, understanding that high inflation implies rapidly increasing cost of living).

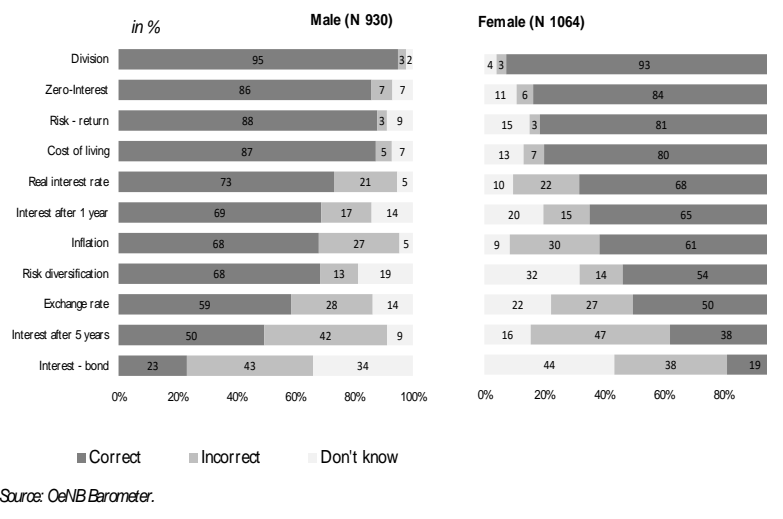

Figure 2. Financial Knowledge of Male and Female Respondents

With an increasing degree of sophistication of the questions the share of correct answers declines rapidly. The question on the link between interest rates and bond prices actually produces more incorrect than correct answers.

Throughout all 11 questions the fraction of respondents giving the correct answer is higher for male than for female respondents. On average over all knowledge questions, men answered $70 \%$ of questions correctly, women only $63 \%$. We can thus confirm the finding in the literature that knowledge gaps of women are larger than those of men. This will be further corroborated by the regression analyses in this paper: The financial knowledge scores (FKS), measured as the number of correctly answered financial knowledge questions, is significantly higher for men than for women.

The results shown in Figure 2 give support to the hypothesis in the literature that gender gaps in financial knowledge may at least partly be related to differences in response behavior: Women indicate more often than men that they don't know the correct answer: For all individual 11 questions, the share of respondents answering with 'Don't know' is higher among female respondents than among men. This difference gets more pronounced when it comes to the most sophisticated questions. On average of all questions, the fraction of 'Don't know'-answers is $18 \%$ for women and $11 \%$ for men.

We may hypothesize that women tend to admit that they do not know the answer instead of just trying the best guess - as their male counterparts often do. While on average the share of incorrect answers among men and women is about equal, women more often declare that they don't know the correct answer. This may at least partly explain the lower share of correct answers. The apparent reluctance of women to make a guess may be related to a higher degree of risk aversion of women, as suggested by several studies [11]. We confirm this finding by analyzing the results of a specific item in our questionnaire that asks about the willingness of respondents to take a risk when investing money.

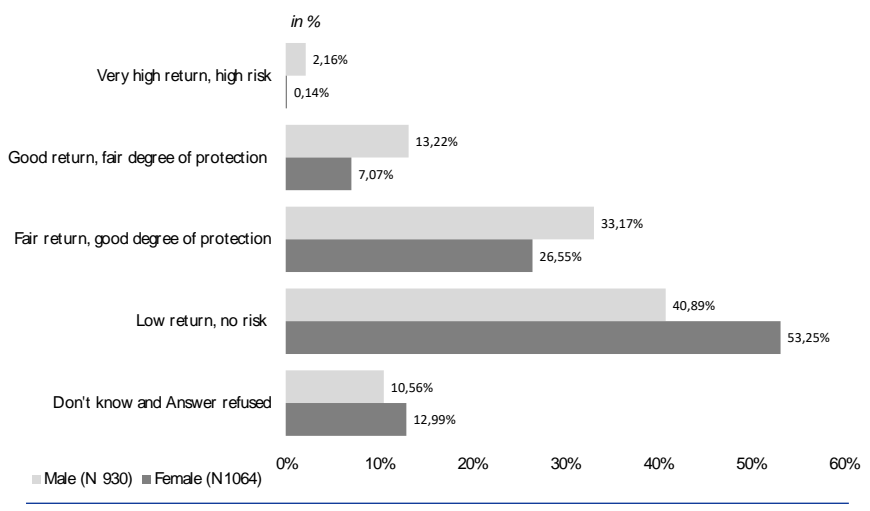

Figure 3. Risk Preferences of Male and Female Respondents

As Figure 3 shows, women are more risk averse than men. A Chi-Square-test confirms a statistically significant gender difference. Most women prefer a low return on their investment as long as there is no risk to lose the invested money. Most men are willing to accept some risk to get a higher return. If this higher 
risk aversion of women also applies to response behavior we should not be surprised to observe the higher tendency to answer, 'Don't know'. Alternatively, women's higher tendency to admit that they do not know the answer may also be the result of a lack of confidence in the own financial capabilities. Men tend to rate their financial knowledge higher than women do [17]. This can only partly be explained by the actually lower knowledge, which will certainly shape the self-assessment. Higher knowledge supports self-confidence in one's own financial capabilities, which in turn gives respondents the courage to answer difficult questions instead of refusing. Additionally, women appear to be more realistic about their financial knowledge. While respondents with low FKS have a tendency to overestimate their own literacy, this effect is less pronounced in the case of women.

The Box-and-Whisker-plots of the number of correct answers given by men and women in Figure 4 impressively shows that the distribution of the second and third quartiles as well as the extensions of the whiskers are almost identical. Therefore, knowing whether a person is a man or a woman would not allow drawing conclusions on this person's financial knowledge. It thus seems desirable to consider more variables to explain a person's level of financial knowledge and it seems wise to consider not only knowledge but also other factors of financial literacy such as financial attitudes or behavior in order to gain a more complete picture. Such an analysis concludes this paper.

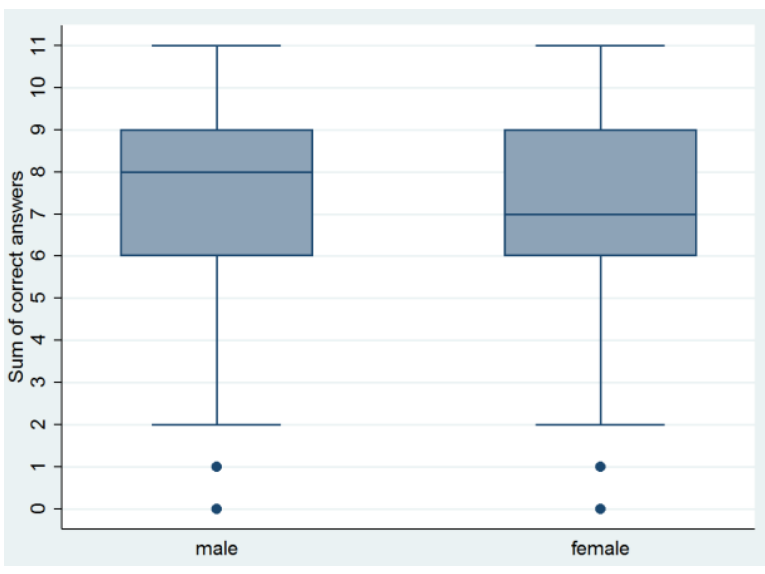

Figure 4. Distribution of Number of Correct Answers Among Male and Female Respondents

Another explanation for the gender gap in financial knowledge may be that the average male respondent in the sample systematically differs from the average female respondent. Men may, for example, have a different educational background than women.

Table 1 shows the major findings of a multivariate regression analysis of the financial knowledge score
FKS on a set of socio-demographic characteristics such as age, education, income, employment status and town size (omitting for brevity the coefficients for employments status and town size since they are mostly insignificant). The coefficients are in line with the international literature, as summarized in Lusardi and Mitchell [2]. Financial knowledge increases with education and income and shows a nonlinear relationship with the age of the respondents. The Austrian data indicate that knowledge is maximized at the age of 51. Financial knowledge is thus lower for the youngest who have only scant experience of work life and financial markets as well as for the eldest who may not be familiar with new financial products and concepts.

Table 1. OLS Regression on Financial Knowledge Score (FKS)

\begin{tabular}{lcc} 
& FKS & FKS \\
\hline Male & $0.63 * * *$ & $0.49 * * *$ \\
Female & & \\
Age & & $0.06 * * *$ \\
Age squared & & $-0.00 * * *$ \\
Education - low & & $-0.99 * * *$ \\
Education - vocational training ${ }^{2}$ & & \\
Education - high & & \\
Income below EUR 2,000 & & $0.68 * * *$ \\
Income EUR 2,000-3,400 & & $-0.32 * *$ \\
Income over EUR 3,400 & & \\
Constant & & 0.19 \\
$\mathrm{~N}$ & $7.06 * * *$ & $5.65 * * *$ \\
R2 & 1994 & 1994 \\
& 0.02 & 0.11
\end{tabular}

Note: Variables in italics are benchmarks for dummy variables. The regression is based on unweighted survey data. Coefficients for the additional controls employment status and town size are omitted given their statistical insignificance.

1 At most completed compulsory education.

2 Apprenticeship; technical, commercial or vocational education 3 Secondary academic or vocational education qualify ing for university education; other education qualify ing for university education; university of applied sciences; technical or vocational college; university: bachelor's, master's and doctoral degrees.

$* \mathrm{p}<0.05, * * \mathrm{p}<0.01, * * * \mathrm{p}<0.001$

Source: OeNB.

The low level of $\mathrm{R}^{2}$ is a common feature of microdata studies on financial knowledge $[6,10]$. As we can only explain about $10 \%$ of the variation in the FKS by socio-demographic variables, important explanatory variables might be missing in the regression model (like the quality and quantity of financial education at home as well as in schools). Most importantly, Table 1 shows that after controlling for socio-demographic characteristics, the gender 
coefficient in the regression analysis shrinks from 0.63 to 0.49 . Comparing financial literacy between men and women of similar socio-demographic characteristics thus reduces the gender gap considerably. However, the coefficient remains positive and statistically significant. Gender differences in financial knowledge are thus not exclusively the result of differences in sociodemographic characteristics.

Several papers have argued that the gender gap may be the result of traditional role models and split of tasks in our society. Women may score worse than men because they work less over their life time, invest less in economic education, work in professions with less economic orientation or have less responsibility for financial matters within their households. The multivariate regression in Table 2 may not fully account for these factors.

We thus repeat the regression analysis for special subgroups of respondents where we may expect that gender differences are smaller than in the total sample. Table 2 shows the gender gap coefficients of these subsample regressions. The same controls are used as in the multivariate regression in table 2 , but for brevity we focus on the gender gap coefficients.

Table 2. OLS Regression on Financial Knowledge for Specific Subgroups

\begin{tabular}{|c|c|c|c|c|c|c|}
\hline & $\begin{array}{c}\text { Highest } \\
\text { education }{ }^{1}\end{array}$ & Young ${ }^{2}$ & $\begin{array}{c}\text { Financial } \\
\text { responsibility }\end{array}$ & Singles & $\begin{array}{c}\text { Divorced \& } \\
\text { widowed }\end{array}$ & $\begin{array}{r}\text { Single-pers } \\
\text { househols }\end{array}$ \\
\hline Male & $0.70^{*}$ & $0.56^{*}$ & $0.55^{* * *}$ & $0.46^{*}$ & 0.24 & 0.28 \\
\hline \multicolumn{7}{|l|}{ Female } \\
\hline $\mathrm{N}$ male & 89 & 143 & 878 & 245 & 152 & 326 \\
\hline $\mathrm{N}$ female & 78 & 190 & 1007 & 202 & 295 & 363 \\
\hline R2 & 0.1 & 0.21 & 0.07 & 0.19 & 0.14 & 0.08 \\
\hline
\end{tabular}

All regressions include a full set of socioeconomic control variables as in Silgoner e al. (2015)

1 Respondents who have completed a bachelor or more (Master's, PhD, etc.).

2 Respondents aged between 15 and 30 .

$* \mathrm{p}<0.05, * * \mathrm{p}<0.01, * * * \mathrm{p}<0.001$

Source: OeNB

First, we could expect a lower gender gap if we limit the regression to the 167 respondents with the highest level of education (completed bachelor's degree or higher), given that financial knowledge increases with education. The first column in Table 3 shows, however, that the gender gap coefficient remains significant at the $5 \%$ level for this subsample and actually increases to 0.7 . This is in line with Mahdavi and Horton [19] who find low financial literacy levels of women even for alumnae from elite female colleges in the U.S.

Second, we may focus on the youngest age cohort. We may hypothesize that the gender gap is related to traditional role models that have lost importance over time. Column 2 of Table 3 ('Young') shows that among the 333 respondents of age 15-30, the gender gap coefficient is still large (0.56) and statistically significant. This is in line with Bucher-Koenen et al. [3] who show that gender differences are present from the start of the life cycle. This is problematic as young people already have to make many important financial decisions. Mandell [20] finds a substantial gender gap in financial literacy even among high school students. Chen and Volpe [12] confirm a gender gap for U.S. college students.

Third, the level of financial responsibility within the household may also influence financial knowledge. Possibly, there is a split of tasks within households and men take most of the financial decisions. This might increase the financial knowledge of men and reduce that of women. Our questionnaire explicitly asks respondents whether they take over financial responsibilities ("Who is responsible for day-to-day decisions about money in your household?'). However, almost all respondents $(1,885$ out of 1,994$)$ declare that they are alone or jointly with their partner responsible for financial decisions. As a result it is not surprising to find no significant differences in the regression results as compared to the baseline regression (column 3 ).

Alternatively, we may thus focus on those who live alone and can thus be assumed to carry financial responsibility. By focusing the analysis on singles (as opposed to married, divorced, separated or widowed, column 4), the gender gap coefficient declines slightly to 0.46 but remains significant at the $5 \%$ level. However, the 'single' variable may not be very appropriate for this purpose because it also includes people in relationships or cohabiting with a partner without marriage. Alternatively, we may thus focus on those 447 respondents who were formerly married but are now divorced or widowed, suggesting that they now need to deal with financial matters independently (column 5). Interestingly, the coefficient is now much smaller for this subgroup and remains insignificant. Having to take financial decisions independently and reconsidering the own financial portfolio may necessitate gathering information on financial issues and foster financial knowledge. We get similar results if we focus on those 689 respondents who live in single-person households (column 6). Again, we may assume that this implies full financial responsibility.

Overall, we confirm the results of earlier studies for the Austrian population: There is a gender gap for financial knowledge, which is still significant if we control for socio-economic characteristics or focus on younger or highly educated respondents. However, the need to assume full financial responsibility within single-person households appears to contribute to the development of financial knowledge so that the gender gap vanishes. 


\section{Differences in Behavior and Attitudes}

According to the OECD definition [1], financial literacy does not only consist of knowledge, but also of awareness, skills, behavior and attitudes. Accordingly, it is interesting to see if there is a gap between women and men not only when it comes to financial knowledge, but also concerning behavior in financial situations and money attitudes.

Table 3. Financial Behavior - Comparisons of Means and Percentages of Agreement

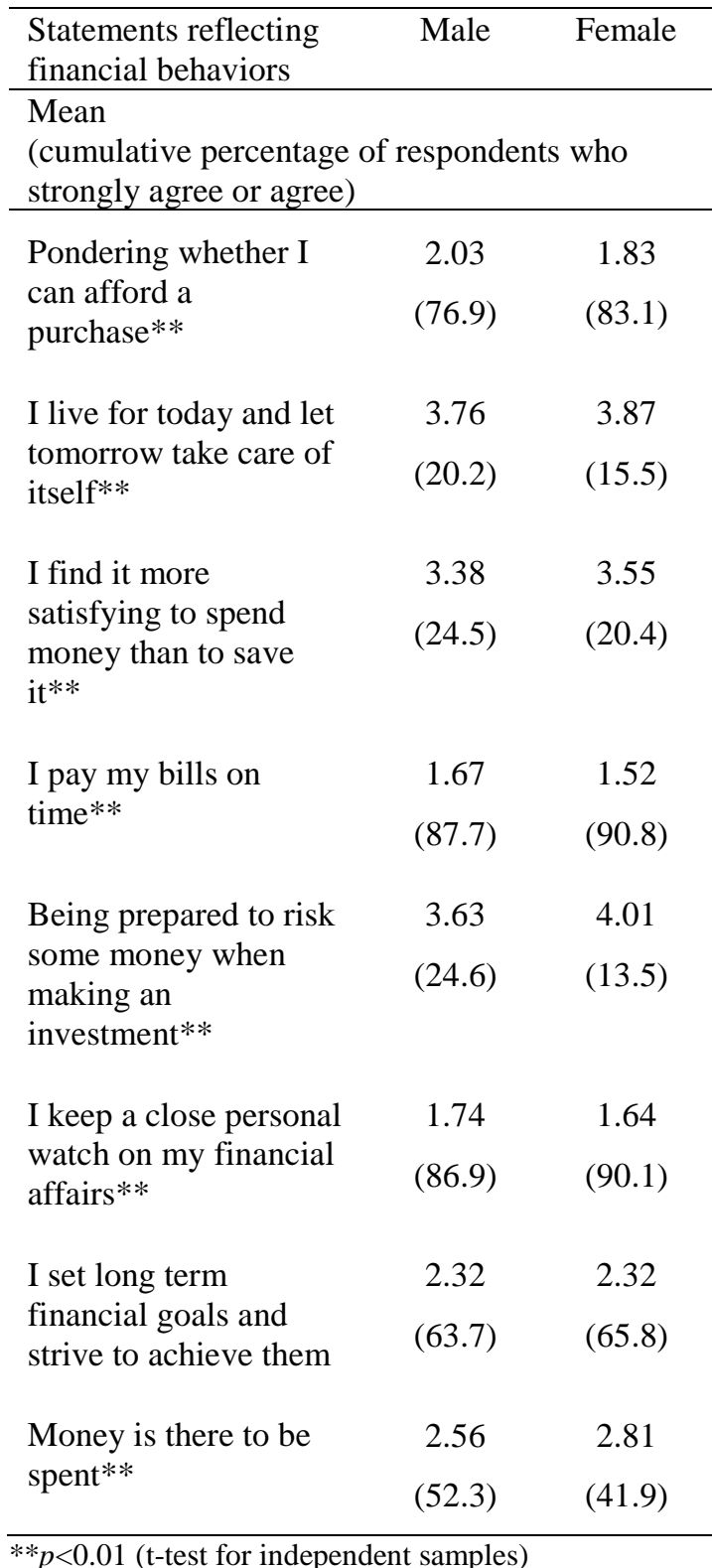

The OECD toolkit for Measuring Financial Literacy [16] comprises eight items that measure various aspects of financial behavior on a five-stepLikert scale ( 1 representing the strongest agreement to the statement and 5 representing the strongest disagreement). Table 3 compares the means and the percentages of agreement to the statements of women and men within our sample.

The comparison of means shows that female financial behavior can be characterized as more prudent and cautious as compared to male financial behavior. Again, there is a gender gap, but this time it is in favor of women. According to their selfevaluations, women have a stronger tendency to reflect their financial situations than men when making purchases. Women also seem to have a closer personal watch on financial affairs than men. Their answers also show a lower agreement to the items reflecting the tendency to spend money rather than saving it. All differences are statistically highly significant except for one item: 'I set long term financial goals and strive to achieve them'. In this case, the means of male and female respondents are statistically equal. But still, the percentage of (strong) agreement to this item is slightly higher for women.

Factor analyses show that the behaviors described above can be summarized by three factors (see table 5). The first factor comprises items like 'pondering whether I can afford the purchase', 'paying bills on time' and 'keeping close personal watch on financial affairs'. Factor loadings of these three items are only high with this first factor and far below 0.3 with the two other factors. We may label the first factor 'cautious planning and saving of money'. Three other items have high loadings on the second factor: 'living for today', 'spending money instead of saving' and 'money is there to be spent'. So, the second factor reflects a behavior pattern that could be labeled 'big spending'. The two remaining items 'setting long term financial goals and strive to achieve them' and 'being prepared to risk some money when making an investment' constitute the third factor and may be summarized as 'risk aware investing'. There is a highly significant difference between men and women concerning the first two factors, showing that women have the tendency to plan and save cautiously. There are comparatively more men who are 'big spenders'.

Our survey questionnaire furthermore comprised a number of questions that reflect financial attitudes and that were added to the OECD/INFE-toolkit for the Austrian survey, namely 15 items from Barry's [18] instrument that intends to measure five attitudes towards money:

- Power: the extent to which respondents think that money means power,

- Importance: money is important,

- Quality: money is needed to gain quality,

- Planning: money needs financial planning and

- Saving: money is something that needs to be saved. 
A factor analysis of the Austrian data confirms the five-factor-structure. Items can thus be combined to sum scores. The differences in money attitudes between men and women are less considerable, but we still find some statistically significant differences. Again, women have more 'favorable' attitudes than men do: they have a higher tendency to think that money needs planning and they are less prone to buying expensive things because they suppose that a higher price stands for higher quality. Women also have a lower tendency to think that money enhances power over other people or situations.

\section{Explaining Financial Well-being}

The OECD definition of financial literacy [1] establishes a link between the three main aspects of financial literacy - knowledge, behavior and attitudes - and financial well-being. Most interestingly, this link has not been empirically investigated yet. We ran a regression analysis to identify the variables that contribute to the explanation of financial well-being. As proxy for financial well-being we suggest using the estimated period of time that people would get along after losing their main source of income, an item that is included in the survey questionnaire.

Table 3 shows a multivariate regression of this proxy of well-being on the financial knowledge score, several measures of behavior and attitudes and a couple of additional control variables: It seems plausible that the higher a persons' income is, the longer he or she will be able to get along without income, because such a person can save money for rainy days. Also, it seems very likely that a person who lives with a partner will probably be able to get along for longer. We furthermore include age and gender as controls.

As expected, the variables 'net income', 'living with a partner' and 'age' all contribute significantly to the variance of the dependent variable and have the expected positive effects. But the analysis also shows that financial knowledge, attitudes and behavior make a considerable and significant additional contribution to explaining financial well-being. The model explains more than $34 \%$ of the variance of the dependent variable, the estimated period of time that people would be able to cover their living expenses after losing their main source of income as an indicator for financial well-being.

Most interestingly, the respondents' gender has no impact on financial well-being in our study. This implies that when it comes to explaining how long a person thinks (s)he can cover his or her living expenses, gender does not make a difference. However financial knowledge, attitudes and behavior do play an important role.
Table 3. Regression Model Explaining Financial Well-being

Dependent variable: estimated period of time that people would be able to cover their living expenses after losing their main source of income

\begin{tabular}{lll}
\hline Independent variables & Beta & t \\
\hline $\begin{array}{l}\text { Number of knowledge } \\
\text { questions answered } \\
\text { correctly }\end{array}$ & $0.125^{* * *}$ & 4.788 \\
& & \\
\end{tabular}

\section{Financial behaviors}

$\begin{array}{llc}\text { cautious planning and } & -0.168 * * * & -6.023 \\ \text { saving } & 0.122 * * * & 4.636 \\ \text { big spending } & -0.080 * * & -2.957\end{array}$

risk aware investing

\section{Attitudes}

Power

0.039

Importance

0.042

Quality

$-0.247 * * *$

Parsimony

$0.143 * * *$

Monthly net income

$0.175^{* * *}$

Living with a partner

$0.137 * * *$

Without partner (Ref.)

Female

0.013

Male (Ref.)

Age

$0.246 * * *$

Const.

5.573

\begin{tabular}{ll}
\hline $\mathbf{R}^{\mathbf{2}} \mathbf{0 . 3 4 9}$ & $* * \mathrm{p}<0.01$ \\
Adj. $\mathbf{R}^{\mathbf{2}} \mathbf{0 . 3 4 2}$ & $* * * \mathrm{p}<0.001$
\end{tabular}

Obviously, a lack of financial knowledge can (at least partially) be compensated by favorable money attitudes and prudent financial behavior.

\section{Conclusions}

It was the aim of this paper to analyze the gender gap in financial literacy between men and women that has been found in many studies [e.g. 1, 3, 4, 5, 9]. In order to do so, we carried out a number of regression analyses to determine the factors that are the best explanations for a person's level of financial 
knowledge as well as his or her level of financial wellbeing.

Overall, we confirm the existence of a gender gap in financial knowledge: Men tend to outperform women in answering knowledge questions. Though the knowledge gaps are similar content-wise, the percentage of men who are able to give the correct answer is always higher than the respective percentage of female respondents. Women show a considerably higher tendency to indicate "I don't know" than men. This leads us to the conclusion that women might be more risk-averse and less willing to make a guess when answering the questions. This gender gap remains significant even if we take different answer behavior and differences in sociodemographic characteristics into account.

Lower financial knowledge of women can be problematic as it may translate into insufficient financial provisions for the future, especially pensions. This is worrisome given high divorce rates and longer live expectancy of women which may lead to a situation in which women at some point in their lives suddenly will have to deal alone with financial matters.

However, the conclusions of prior research that women are less financially literate or a financially vulnerable group cannot be fully supported. Most interestingly, the respondents' gender is irrelevant for explaining financial well-being in our study. Though women answer significantly less knowledge questions correctly than men, they outperform men when it comes to prudent financial behavior and they also show more favorable money attitudes. They are in fact more risk averse and have a higher tendency to carefully plan their financial affairs. More prudent attitudes might - to some extent - compensate for the lack in financial knowledge. These factors are important explanations for financial well-being, along with income, age and living with a partner. A regression analysis on an indicator of financial wellbeing shows that while knowledge, behaviors and attitudes are important and statistically significant explanations for financial well-being, gender clearly is not.

However, we would need more variables measuring financial well-being to confirm this hypothesis. It would be desirable to learn more about important financial decisions, how they are made and how people - no matter if male or female - can be effectively supported to make sound decisions and achieve financial well-being. These insights could be used to improve financial education programs and interventions for fostering financial literacy, both for men and women. Anyway, supporting women to acquire more financial knowledge might support them to gain more confidence in financial situations and lead more independent financial lives.

\section{References}

[1] Atkinson, A. and F. Messy. Measuring Financial Literacy: Results of the OECD/International Network on Financial Education (INFE) Pilot Study, OECD Working Papers on Finance, Insurance and Private Pensions, No. 15, OECD Publishing. 2012.

[2] Lusardi, A. and O. S. Mitchell. The Economic Importance of Financial Literacy: Theory and Evidence. Journal of Economic Literature 52(1), 2014, pp. 5-44.

[3] Bucher-Koenen, T., A. Lusardi, R. J. M. Alessie and M. C. J. van Rooij. How financially literate are women? NBER Working paper No. w20793, 2014.

[4] Arrondel, L., M. Debbich and F. Savignac. Does financial literacy influence financial decisions? Rue de la Banque 2/2014, 2014, pp. 1-5.

[5] Wagland, S.P. and S. Taylor. When it comes to financial literacy, is gender really an issue? Australasian Accounting Business and Finance Journal 3(1), 2009, pp. 13-25.

[6] Fonseca, R., K. J. Mullen, G. Zamarro and J. Zissimopoulos. What explains the gender gap in financial literacy? RAND Working Paper WR-762. 2010.

[7] Brown, M. and R. Graf. Financial literacy and retirement planning in Switzerland. Numeracy 6(2), Article 6, 2013.

[8] Hsu, J. W. Aging and strategic learning: The impact of spousal incentives on financial literacy. Federal Reserve Boards Working Paper 2011-53.

[9] Lührmann, M., M. Serra-Garcia and J. Winter. The effects of financial literacy training: Evidence from a field experiment in German high schools. Beiträge zur Jahrestagung des Vereins für Socialpolitik 2013: Wettbewerbspolitik und Regulierung in einer globalen Wirtschaftsordnung - Session: Household Behavior, No. C12-V2, 2013.

[10] Bucher-Koenen, T. and B. Lamla. The long shadow of socialism: On East-West German differences in financial literacy, Munich Center for the Economics of Aging. Discussion Paper, 2014, pp. 282-2014.

[11] Powell, M. and D. Ansic. Gender differences in risk behavior in financial decision-making: An experimental analysis. Journal of Economic Psychology 18(6), 1997, pp. 605-628.

[12] Chen, H. and R. P. Volpe. Gender differences in personal financial literacy among college students. Financial Services Review 11, 2012, pp. 289-307.

[13] Mottola, G. R. In our best interest: women, financial literacy and credit card behavior. Insights: American Fiancial Capability - April 2012, pp. 1-6.

[14] Van Rooij, M., A. Lusardi and R. Alessie. Financial literacy and stock market participation. Journal of Financial Economics 101, 2011, pp. 449-472. 
[15] OECD. OECD/INFE International Survey of Adult Financial Literacy Competencies. OECD, Paris. 2016.

[16] OECD. OECD/INFE toolkit for measuring financial literacy and financial inclusion. OECD, Paris. 2015.

[17] Barber, B. M. and T. Odean. Boys will be boys: Gender, overconfidence and common stock investment. The Quarterly Journal of Economics (2) 2001, pp. 261-291.

[18] Barry, D. Die Einstellung zu Geld bei jungen Erwachsenen. Wiesbaden: Springer, 2014.

[19] Barry, D. Die Einstellung zu Geld bei jungen Erwachsenen. Wiesbaden: Springer, 2014.

[20] Mandell, L. Financial education in high school, in Overcoming the saving slump: How to increase the effectiveness of financial education and saving programs, ed. A. Lusardi, Chicago: University of Chicago press, 2008, pp. 257-279. 